ERRATUM

Cornelia Fürstenau • Franz W. Badeck

Petra Lasch • Manfred J. Lexer • Marcus Lindner

Peter Mohr • Felicitas Suckow

\title{
Multiple-use forest management in consideration of climate change and the interests of stakeholder groups
}

Published online: 6 May 2006

(C) Springer-Verlag 2006

\section{Eur J Forest Res (2006) DOI 10.1007/s10342-006-0114-x}

Please note, that unfortunately Fig. $4 \mathrm{a}-\mathrm{c}$ contains incorrect data. The utility of the partial objective income from timber production and subsequently the overall utility is in most cases too high in the originally published figure.
The online version of the original article can be found at http:/ dx.doi.org/10.1007/s10342-006-0114-x

C. Fürstenau $(\varangle) \cdot$ F. W. Badeck · P. Lasch · F. Suckow Department of Global Change and Natural Systems,

Potsdam Institute for Climate Impact Research,

P.O. Box 601203, 14412 Potsdam, Germany

E-mail: c.fuerstenau@gmx.de

Tel.: + 49-331-2882632

Fax: + 49-331-2882417

\section{J. Lexer}

Institute of Silviculture,

BOKU_-University of Natural Resources

and Applied Life Sciences,

Vienna, Austria

\section{Lindner}

European Forest Institute, Joensuu, Finland

P. Mohr

Wald, Umwelt, Mensch, Werbig, Germany
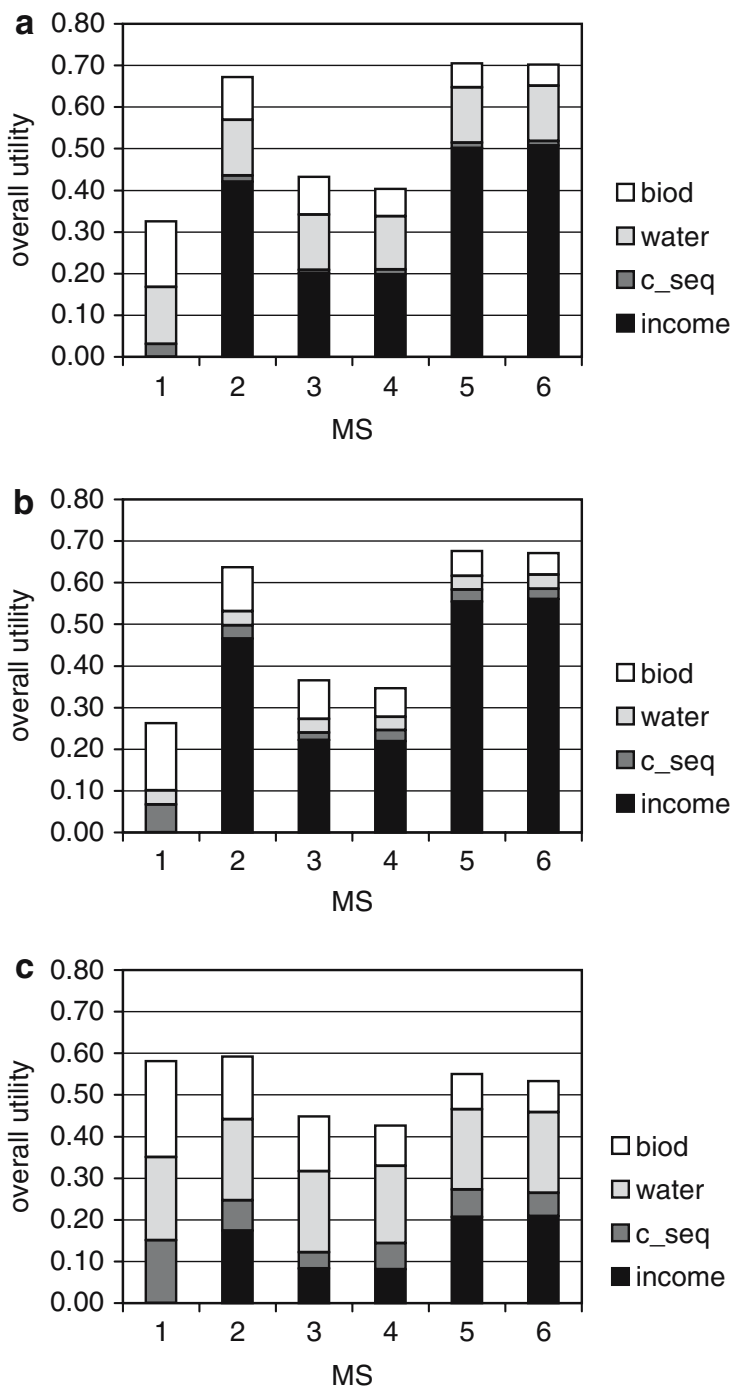

Fig. 4 a-c Overall and partial utilities (biod biodiversity, water groundwater recharge, $c_{-} s e q$ carbon sequestration, and income) of management strategies $(M S$, compare Table 3$)$ under the preference setting of the forest manager of public-owned forest $(F M)$ (Fig. 6a), the private forest owner (FO) (Fig. 6b), and the environmental organisation $(E O)$ (Fig. $6 \mathrm{c})$ 